\title{
Pharmacological actions of statins: potential utility in COPD
}

\author{
R.P. Young*, R. Hopkins* and T.E. Eaton ${ }^{\#}$
}

ABSTRACT: Chronic obstructive pulmonary disease (COPD) is characterised by minimally reversible airflow limitation and features of systemic inflammation. Current therapies for COPD have been shown to reduce symptoms and infective exacerbations and to improve quality of life. However, these drugs have little effect on the natural history of the disease (progressive decline in lung function and exercise tolerance) and do not improve mortality. The anti-inflammatory effects of statins on both pulmonary and systemic inflammation through inhibition of guanosine triphosphatase and nuclear factor- $\mathrm{K}$ mediated activation of inflammatory and matrix remodelling pathways could have substantial benefits in patients with COPD due to the following. 1) Inhibition of cytokine production (tumour necrosis factor- $\alpha$, interleukin (IL)-6 and IL-8) and neutrophil infiltration into the lung; 2) inhibition of the fibrotic activity in the lung leading to small airways fibrosis and irreversible airflow limitation; 3) antioxidant and anti-inflammatory (IL-6 mediated) effects on skeletal muscle; 4) reduced inflammatory response to pulmonary infection; and 5) inhibition of the development (or reversal) of epithelial-mesenchymal transition, a precursor event to lung cancer. This review examines the pleiotropic pharmacological action of statins which inhibit key inflammatory and remodelling pathways in COPD and concludes that statins have considerable potential as adjunct therapy in COPD.

\section{KEYWORDS: Chronic obstructive pulmonary disease, statins}

hronic obstructive pulmonary disease (COPD) occurs as a result of the combined effects of smoking exposure and genetic susceptibility to the damaging effects of smoking. COPD is characterised by progressive, minimally reversible airflow limitation that results from varying combinations of parenchymal destruction (emphysema) and fixed small airways disease from smooth muscle hypertrophy and airway fibrosis [1-3]. COPD is also a systemic disease with progressive muscle wasting of the skeletal and respiratory system, which further limits exercise capacity [4-6]. Other systemic manifestations of COPD include coronary artery disease (CAD), osteoporosis and anaemia [4,7]. Although goblet cell hyperplasia and excessive mucus production are also clinical manifestations in COPD they do not appear to be associated with poor outcomes in COPD, unlike reduced expiratory volumes and systemic inflammation [3].

\section{PATHOPHYSIOLOGY OF COPD}

Smoking has been shown to account for $\sim 85 \%$ of cases diagnosed with COPD, while exposure to other aero-pollutants such as organic and inorganic work dusts, heavy air pollution or precipitants of allergic inflammation may also play a role [3]. The potential effects of smoking on the lung, systemic circulation and muscle is shown in figure 1. Smoking initiates a ubiquitous inflammation orchestrated by the bronchial epithelium with release of interleukin (IL)-8 and subsequent sequestration of neutrophils from the pulmonary capillaries into respiratory bronchioles and airway lumen [8-10]. IL-8 stimulates further release of neutrophils from the bone marrow [9]. Activated neutrophils in the pulmonary tissue (respiratory bronchioles and alveolar walls) release neutrophil elastase which contributes to elastin degradation [8]. Other proteases with possible roles in COPD include sereine proteases, cysteine proteases or chymotrypsin. Smoke exposure also incites the release of other inflammatory cytokines from a variety of cells including IL-6, tumour necrosis factor (TNF)- $\alpha$, IL$1 \beta$, transforming growth factor (TGF)- $\beta 1$ and granulocyte-monocyte colony-stimulating factor (GM-CSF) [1, 11]. Inhalation of cigarette smoke results in a huge exogenous oxidant load on the

\section{AFFILIATIONS}

*Dept of Medicine, University of Auckland, and

\#Dept of Respiratory Services, Auckland City Hospital, Auckland, New Zealand.

\section{CORRESPONDENCE}

R.P. Young

Dept of Medicine

Auckland Hospital

Private Bag 92019

Auckland

New Zealand

E-mail: roberty@adhb.govt.nz

Received:

Aug 242009

Accepted:

Sept 022009

PROVENANCE

Submitted article, peer reviewed. 
lung from reactive oxygen species (ROS), which inactivates many of the anti-protease mediators, most notably $\alpha_{1}$-antitrypsin (and possibly $\alpha_{1}$-anti-chymotrypsin and serine antiproteases), resulting in an acquired anti-protease deficiency [12,13]. The effect of IL-8 and neutrophil influx into the pulmonary parenchyma is accompanied by the influx of macrophages and CD8+ Tlymphocytes [14]. Macrophages are thought to become activated and release a number of matrix metalloproteases (most notably MMP1, MMP2, MMP9, MMP12 and MMP15), which have the ability to degrade both elastin and collagen leading to further lung parenchymal damage [10, 11, 15]. The neutrophils are known to release a high concentration of endogenous oxidants, which add to those derived from smoking and worsen the global anti-protease effect through inactivation of systemic anti-proteases (e.g. $\alpha_{1}$-antitrypsin) and inhibition of local anti-proteases (e.g. tissue inhibitors of metalloproteinases) [8].

The oxidant load derived from the lung (exogenous and endogenous) crosses the endothelium where, in combination with elevated circulating cytokines, it results in systemic inflammation in the vascular system $[4,7,12]$. Nicotine from smoke provides agonist activity to the nicotine acetylcholine receptor found throughout the airways and is thought to initiate the release of fibronectin leading to pulmonary airway fibrosis by fibroblasts [16, 17]. The latter is thought to be mediated by IL- 8 and TGF- $\beta 1$ is released as part of the inflammatory responses [16, 17] leading to excess collagen relative to elastin (impaired repair). Finally, recent studies suggest that dysregulated apoptosis (programmed cell death) of structural cells (epithelial and endothelial cells) and inflammatory cells (polymorphic neutrophils) occurs in patients with COPD $[18,19]$. It has been shown that neutrophil apoptosis is reduced in the sputum of patients with COPD and is associated with elevated IL-6 and IL-8 levels [19]. This observation was found to be mediated by nuclear factor (NF)$\kappa \mathrm{B}$ activation and is consistent with other studies that show these cytokines are associated with inhibition of apoptosis [20]. Prolonging the lifespan of neutrophils in the lung would result in persisting neutrophil-mediated inflammation and matrix remodelling.

It has also been proposed that high levels of cytokines (primarily IL-6), inflammatory mediators and/or ROS in the systemic circulation, derived in a large part from the

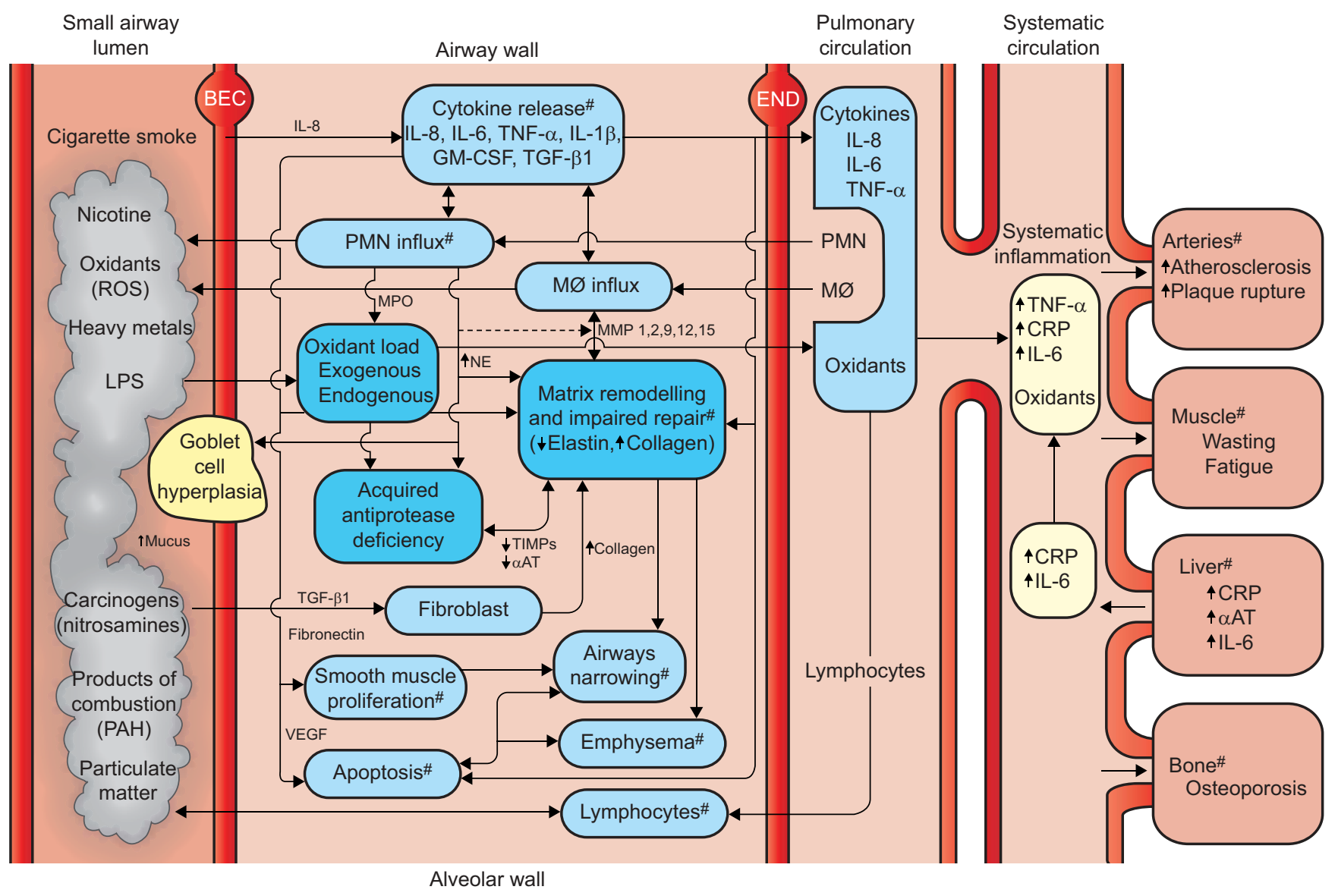

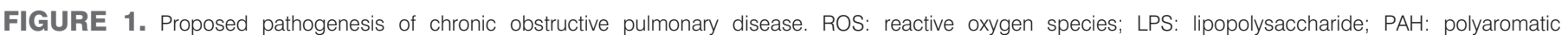

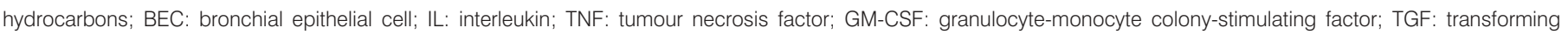

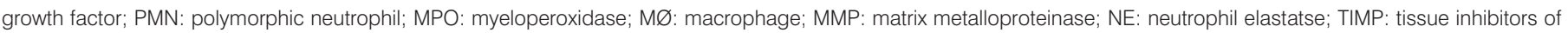
metalloproteinase; $\alpha \mathrm{AT}$ : $\alpha_{1}$-antitrypsin; VEGF: vascular endothelial growth factor; END: endothelial cell; CRP: C-reactive protein. ${ }^{\#}$ : denotes the site of action of statins. 
pulmonary circulation (the "spill over" effect) [4, 7], may lead to muscle wasting and decreased muscle function [17-22]. Apoptosis has also been implicated in muscle wasting, as seen in COPD patients $[18,19]$, and may be important in survival [19-22]. Collectively, smoking appears to incite an inflammatory response and high oxidant load that, over time, prematurely ages the body [23] through lung destruction (emphysema), poor elastic recoil of tissues (reduced airway compliance), maladaptive or excessive healing (airway fibrosis), and wasting of skeletal and respiratory muscles resulting in poor exercise tolerance. These processes are "exaggerated" in smokers who are genetically predisposed to COPD and result in progressive loss of lung function, muscle wasting and exercise intolerance.

There is growing epidemiological and molecular evidence that COPD is closely associated with lung cancer [24-26]. Like COPD, lung cancer develops in only the minority of long-term smokers, estimated to be 10-15\% [27]. Recently, it has been shown that $60-90 \%$ of those diagnosed with lung cancer have pre-existing impaired lung function (consistent with COPD) and/or emphysema on computed tomography scanning [2426]. This relationship is comparable to that observed between obesity and type 2 diabetes. These epidemiological studies suggest that factors conferring susceptibility to COPD may also confer susceptibility to lung cancer mediated through genetic variants underlying the pathogenic pathways, as described above and as shown in figures 1 and 2 [28].

There is also a growing interest in the role that epithelialmesenchymal transition (EMT) plays in lung carcinogenesis (fig. 2) [29, 30]. In this process, bronchial epithelial cell (BEC) integrity and function is disrupted by matrix remodelling and growth factor release that underlies COPD, such as TGF- $\beta$ and MMPs, and promotes EMT. The effect of growth factors on EMT has been shown to be promoted by collagen 1, linking remodelling (COPD) with EMT [30]. In animal models, the guanosine triphosphatase (GTPase) proteins (i.e. GTP-binding proteins e.g. Ras, Rho and Rac) have been linked to the development of lung cancer, with NF- $\mathrm{BB}$ mediating this effect in a COPD mouse model [31]. In vitro studies show that inhibition of GTPase can reverse EMT and restore the epithelium to its normal morphology [32]. Finally, there is a link between EMT and damage to DNA which results in the formation of DNA adducts and somatic mutations forming oncogenes (e.g. k-Ras) and inhibiting tumour suppressor genes, which are thought to underlie lung cancer development [31]. Although several pathological pathways are likely to be involved in the development of COPD and EMT (figs 1 and 2), many are mediated intracellularly by GTPases [29]. These signalling molecules require isoprenylation to be active and, as described above, are critical for cellular function through upregulating effects on transcription binding factors, such as NF$\kappa \mathrm{B}$ and activator protein-1, central to gene expression in COPD [33] and lung cancer development [29]. If EMT is an important pre-malignant event then the inflammation and matrix remodelling processes that lead to COPD may also lead to lung cancer, thereby explaining this close relationship in an overlapping group of genetically susceptible smokers [28]. If this were true, then any pharmacological agent that could attenuate the inflammatory and matrix remodelling processes underlying COPD might also reduce the risk (and development) of lung cancer.

\section{EPIDEMIOLOGY OF COPD}

Despite the inflammatory and aging effects of smoking on not just the lungs but the arteries and muscles of the body, why do only an estimated $20 \%$ of smokers develop clinically significant COPD [3]? Numerous studies have shown that COPD and lung function have a strong genetic component, especially in the presence of smoking history [34-36]. Based on widely divergent drug metabolite levels, classic pharmacogenetic studies have been able to define high or low drug metabolisers that were subsequently linked to genetic variants of metabolising enzymes [37]. Similarly, after $\geqslant 40$ yrs of smoking, forced expiratory volume in $1 \mathrm{~s}$ (FEV1) in smokers can be categorised according to approximately bi- or tri-modal distribution with the majority (70-80\%) maintaining normal (or near normal) lung function (termed resistant smokers), while the remainder have accelerated decline in FEV1 and are identified as susceptible [3, 38-40]. This latter group may eventually be diagnosed with COPD; however, due to the insidious breathlessness and under-utilisation of spirometry, $50-80 \%$ of people with COPD remain undiagnosed [41].

This susceptibility to the effects of smoking is conferred by a variable combination of low penetrant variants in genes encoding proteins that are closely linked to the pathogenic pathways described above [42]. It has been proposed that reduced FEV1 in smokers is a general barometer of a smoker's susceptibility to the adverse effects of smoking and explains the reported two to five-fold increased risk of other smoking related complications, such as CAD, lung cancer and stroke, in comparison to smokers with normal lung function [38]. It has been shown that both cardiovascular and all-cause mortality are more closely linked to reduced FEV1 than to smoking status $[43,44]$, and maybe mediated by over-lapping inflammatory mediators (e.g. C-reactive protein (CRP), TNF- $\alpha$ and IL-6). Therefore, smoking is an accelerant to an established proinflammatory tendency which may be genetically conferred $[28,45]$ and may lead to premature aging of the lungs and arteries.

\section{CURRENT TREATMENT IN COPD}

The mainstay of treatment in COPD is short- and long-acting $\beta$ agonist therapy to relax smooth muscle and dilate airways [2]. This approach is very successful in relieving the brochoconstriction in asthma where hyperreactive airways and smooth muscle constriction are important. The bronchodilating response to this treatment is considerably less in COPD due to small airway fibrosis and emphysema secondary to matrix remodelling (imbalance of elastin/collagen content). Inhaled corticosteroids are also used to inhibit airway inflammation of COPD although it is strongly neutrophil driven rather than the T-helper (TH) type-2 inflammatory response of asthma, where activated lymphocytes are thought to play a central role [2]. Given these significant differences in pathogenic pathways underlying COPD and asthma, it is perhaps not surprising that current treatments in COPD modestly improve symptoms but do no restore patients back to normal lung function. Given that corticosteroids do little for neutrophilic inflammation [2, 11], it is also not surprising that COPD is characterised by a 


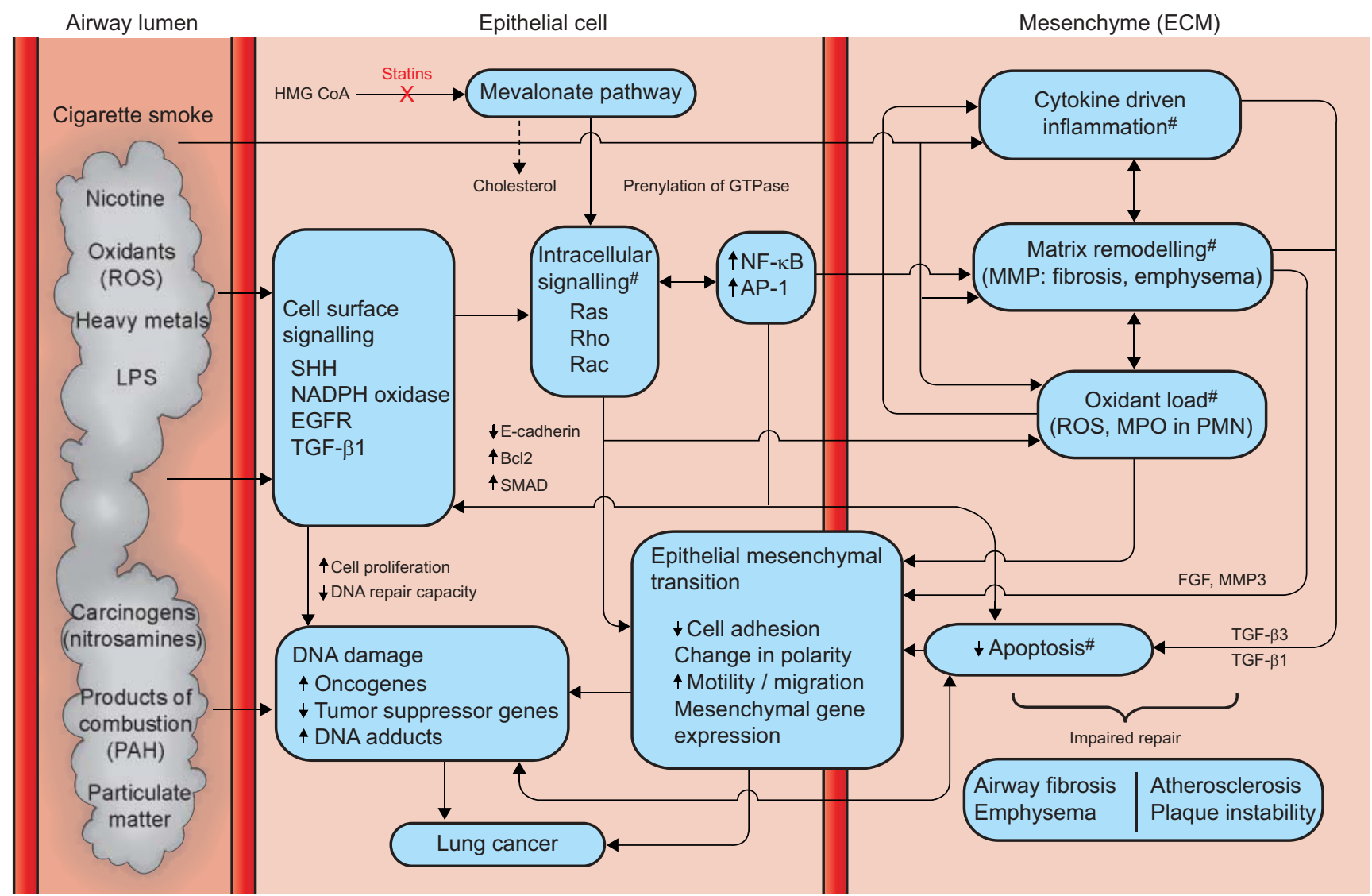

FIGURE 2. Proposed pathogenesis of lung cancer. ECM: extracellular matrix; ROS: reactive oxygen species; LPS: lipopolysaccharide; PAH: polyaromatic hydrocarbons; HMG CoA: 3-hydroxy-3-methylglutaryl coenzyme A; GTPase; guanosine triphosphatase; SHH: sonic hedgehog homologue; NADPH: reduced nicotinamide adenine dinucleotide phosphate; EGFR: epidermal growth factor receptor; TGF: transforming growth factor; NF-kB: nuclear factor-kB; AP-1: activator protein-1; MMP: matrix metalloproteinase; MPO: myeloperoxidase; PMN: polymorphic neutrophil; FGF: fibroblast growth factor. * : denotes the site of action of statins.

progressive decline in lung function, exercise tolerance and premature death despite these treatments. Although some studies suggest marginal benefits on mortality from inhaled corticosteroids or combined $\beta$-agonist/corticosteroid therapy, the data are not terribly convincing [46-48]. Based on these limitations [49,50], interest has turned to treatments with greater impact on neutrophil or macrophage derived inflammation [50-53].

\section{COPD AND SYSTEMIC INFLAMMATION}

There are a growing number of studies showing that CRP is a marker of systemic inflammation and a possible effector molecule in vascular disease [4-6]. Several cross-sectional and prospective studies have shown the close inverse relationship between high-sensitivity CRP and lung function [54-56]. CRP is synthesised and released by the liver into the systemic circulation in response to IL-6 released by inflammatory stimuli. This link between IL-6, CRP and COPD is supported by population studies showing an inverse relationship between serum IL-6 levels and FEV1 $[5,57,58]$, and murine models of emphysema resulting from IL-6 overexpression [59]. Interestingly, $\alpha_{1}$-antitrypsin is also an acute-phase protein released by the liver at the time of inflammation. It should be noted that serum IL6 and IL-8 levels are elevated in smokers with COPD in excess of those with normal lung function $[8,11$, 19]. It would appear conceivable that, in those disposed to COPD, smoking initiates an increase in the cytokines IL- 6 and IL-8 which might underlie the systemic ("spill over" effect [4, 7]) and pulmonary inflammation, respectively. This could explain the observation that patients with COPD have a greater than two-fold risk of coronary heart disease [6]. Genetic variation may confer important effects on the expression of these effector molecules (e.g. CRP, IL-6 and IL-8) that then mediate the downstream effects on COPD [60] and lung cancer $[45,61,62]$. The heavy oxidant load derived from smoking has effects both locally in lung parenchyma and systemically on muscle function. Given these diverse pathways and anatomically distant events, what evidence exists to suggest that statin therapy (or 3-hydroxy-3-methylglutaryl coenzyme A reductase inhibitors) might affect any of these pathological events?

\section{STATIN EFFECTS ON CLINICAL OUTCOMES IN COPD: AN OVERVIEW}

Statins are known to inhibit endogenous cholesterol synthesis in hepatocytes by blocking the synthesis of cholesterol in the mevalonate pathway. This explains the ability of statins to 
lower serum cholesterol. However, evidence from both human and animal studies has shown that statins have strong immune-modulating effects in both the systemic [63] and pulmonary circulation [64, 65], which may have useful antiinflammatory actions in COPD (table 1) [52, 65-88].

Recently, there have been a number of observational studies suggesting that patients with COPD and taking statins have reduced hospitalisation for COPD exacerbations, lower mortality from COPD exacerbations (or chest infections) and lower cardiovascular mortality compared to those not taking statins (fig. 3) [89, 91-95]. In three recently published reviews, beneficial effects were consistently found in those taking statins [66, 99, 100] and appear to be irrespective of concomitant corticosteroid use [67]. In addition to these reported benefits, several observational studies have shown that statin use also reduces decline in FEV1 and lowers the risk of lung cancer (fig. 3) (reviewed in [66, 90, 96-98, 101]). A number of observational studies have also examined the effect of taking statins in patients from the general population with

TABLE 1 Summary of statin mediated pharmacological effects on pulmonary inflammation and remodeling

COPD pathway Study type Statin effect on pathogenic pathways [Ref.]

\begin{tabular}{|c|c|c|c|}
\hline \multirow[t]{5}{*}{ Cytokine production } & $\begin{array}{l}\mathrm{MM}, \mathrm{HM} \text { in vitro (liver cell line), } \mathrm{HM} \\
\text { in vivo (mononuclear cells) }\end{array}$ & Reduce IL-6 induced CRP production by hepatocytes & {$[52,67,68]$} \\
\hline & $\begin{array}{l}\text { HM in vitro (VSM cells and PBE } \\
\text { cells) }\end{array}$ & Reduce IL-8 production by VSM cells & {$[69,70]$} \\
\hline & MM & Inhibition of neutrophil accumulation and IL-8 and TNF- $\alpha$ concentration in BALF in rats & [71] \\
\hline & HM in vivo (serum), MM & Reduce production of IL- $\beta 1$ and TNF- $\alpha$ & {$[52,72]$} \\
\hline & MM & Reduced expression of IFN- $\gamma$ TNF- $\alpha$ and MMP12 in whole lung & [73] \\
\hline \multirow[t]{2}{*}{ Matrix remodelling } & MM & Reduced lung parenchymal destruction and MMP 9 activity in smoke exposed rat lung & {$[74,75]$} \\
\hline & $\begin{array}{l}\text { HM ex vivo (bronchial epithelial } \\
\text { cells) }\end{array}$ & $\begin{array}{l}\text { Reduce release of MMP2 and MMP9 from bronchial epithelial cells from } \\
\qquad \text { lung transplant patients }\end{array}$ & [70] \\
\hline \multirow[t]{6}{*}{$\begin{array}{l}\text { Neutrophil/macrophage } \\
\text { influx }\end{array}$} & $\begin{array}{l}\text { HM ex vivo (bronchial epithelial } \\
\text { cells), HM in vivo (PMN) }\end{array}$ & $\begin{array}{l}\text { Reduce neutrophil influx in lung transplant recipients by inhibiting release of } \\
\qquad \text { IL-8 and GM-CSF from bronchial epithelial cells }\end{array}$ & {$[70,76,77]$} \\
\hline & $\begin{array}{l}\mathrm{HM} \text { in vitro (PMN), } \\
\mathrm{HM} \text { in vivo (serum) }\end{array}$ & Reduce neutrophil endothelial adhesion and transendothelial migration & {$[76,78-80]$} \\
\hline & MM & $\begin{array}{l}\text { Reduce neutrophil influx and inhibit the development of elastase induced } \\
\text { pulmonary emphysema in mice }\end{array}$ & {$[74,75]$} \\
\hline & $\begin{array}{l}\text { MM, HM ex vivo } \\
\text { (human monocytes) }\end{array}$ & $\begin{array}{l}\text { Reduce CRP-induced monocyte migration by inhibition of } \\
\qquad \text { ICAM- } 1 \text { in human monocytes }\end{array}$ & [81] \\
\hline & $\begin{array}{l}\mathrm{MM}, \mathrm{HM} \text { in vitro (endothelial cells), } \\
\qquad \mathrm{HM} \text { in vivo (BALF) }\end{array}$ & Reduced concentration of neutrophils and lymphocytes in BALF & {$[74,75]$} \\
\hline & $\mathrm{MM}, \mathrm{HM}$ in vitro & $\begin{array}{l}\text { Reduce chemokine and adhesion molecule expression to reduce migration of } \\
\text { inflammatory cells into the airways }\end{array}$ & {$[74,81,82]$} \\
\hline \multirow{3}{*}{$\begin{array}{l}\text { Epithelial/endothelial } \\
\text { integrity }\end{array}$} & MM & Promotes alveolar cell regeneration and restores endothelial cell function & [75] \\
\hline & MM & $\begin{array}{l}\text { Reduce LPS-induced IL-6 gene expression leading to reduced lung vascular leak and } \\
\text { pulmonary inflammation in mice lung }\end{array}$ & [83] \\
\hline & $\begin{array}{l}\text { HM in vitro (endothelial and smooth } \\
\text { muscle cells) }\end{array}$ & Inhibition of VEGF in smooth muscle cells and endothelial cells & [84] \\
\hline \multirow[t]{2}{*}{ Apoptosis } & $\begin{array}{l}\mathrm{HM} \text { in vitro (macrophages } \\
\text { and PMN) }\end{array}$ & $\begin{array}{l}\text { Enhances clearance of apoptotic cells in alveolar } \\
\text { macrophages from patients with COPD }\end{array}$ & [85] \\
\hline & $\begin{array}{l}\text { HM in vitro (endothelial cells), HM in } \\
\text { vitro (endothelial and smooth } \\
\text { muscle cells) }\end{array}$ & Increase apoptosis in human vascular endothelial cells & {$[84,86]$} \\
\hline \multirow[t]{2}{*}{ Oxidant response } & $\mathrm{HM}$ in vivo (PMN) & Reduce IL-8 release from neutrophils and neutrophil derived reactive oxidant species & [77] \\
\hline & HM in vivo (serum), MM & Strong anti-oxidant properties & {$[87,88]$} \\
\hline Mucus production & MM & $\begin{array}{l}\text { Reduced LPS-induced goblet cell hyperplasia in bronchial epithelium and Muc5A } \\
\text { induced mucus hypersecretion }\end{array}$ & [71] \\
\hline CRP level & HM in vitro (liver cell) & $\begin{array}{l}\text { Reduce CRP levels at the transcriptional level thorough Rac-1 mediated inhibition of } \\
\text { STAT3 phosphorylation }\end{array}$ & [67] \\
\hline
\end{tabular}

COPD: chronic obstructive pulmonary disease; CRP: C-reactive protein; MM: murine model; HM: human model; VSM: vascular smooth muscle; PBE: primary bronchial epithelial; PMN: polymorphic neutrophil; BALF: bronchoalveolar lavage fluid; IL: interleukin; TNF: tumour necrosis factor; IFN: interferon; MMP: matrix metalloproteinase; GM-CSF: granulocyte-monocyte colony-stimulating factor; ICAM: intracellular adhesion molecule; LPS: lipopolysaccharide; VEGF: vascular endothelial growth factor. 


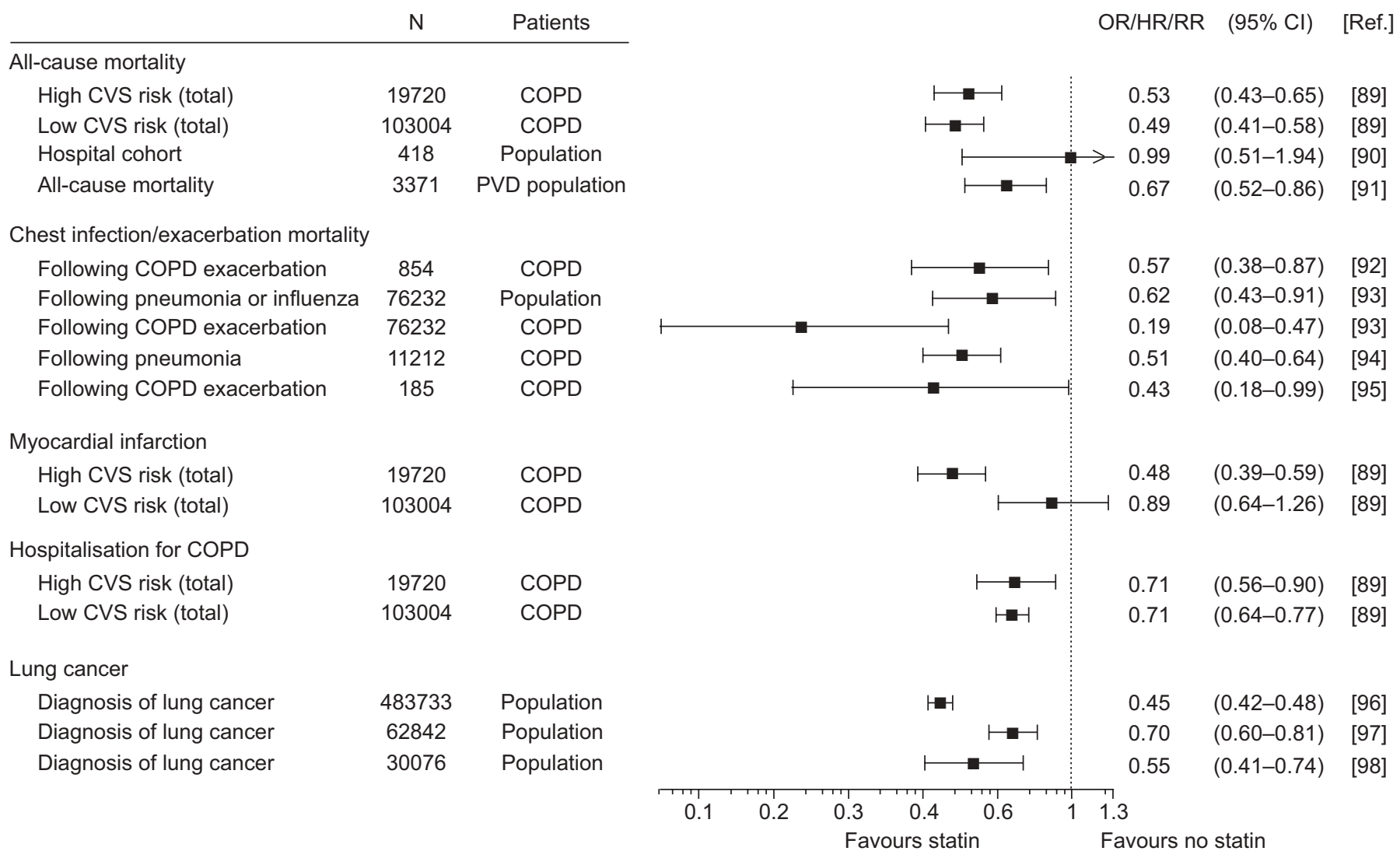

FIGURE 3. Morbidity and mortality benefits with statin use in observational studies on a logarithmic scale. CVS: cardiovascular; COPD: chronic obstructive pulmonary disease. Data are presented as odds ratio (95\% confidence interval), except hospital cohort which is presented as relative risk (95\% confidence interval) and following COPD exacerbation which is presented as hazard ratio ( $95 \%$ confidence interval).

community acquired pneumonia (table 2) [102-109]. However, unlike the studies in COPD, the results in pneumonia are not consistent. This probably reflects the heterogeneity of the study populations with respect to many possible confounding factors (e.g. sampling, age and smoking) but specifically the presence of COPD (where systemic-pulmonary inflammation is preexisting) [7].

Such diverse and clinically significant benefits in patients with COPD might, at first glance, appear unlikely to be attributable to a single drug (figs 1 and 2). Indeed, some benefits from statin use have been attributed to the "healthy user effect"; however, there is little, if any, convincing data to support this hypothesis [66]. Importantly, statin use in patients with COPD should be associated with greater mortality (confounding by indication) due to the consistently higher incidence of coexisting cardiovascular diseases [89-93, 96-98, 101]; 48\% of statin users have CAD versus $8 \%$ in nonusers [66]. Yet in patients with COPD, despite comparable lung function [66], statin use consistently confers lower mortality compared to nonuse. It was estimated from the observational studies that $25-30 \%$ of patients with COPD are currently prescribed statins [66].

The data from randomised control trials (RCTs) examining statin use in COPD is limited to just two studies [110,111]. In a sub-analysis of a large randomised trial of statin therapy and its effects on cardiovascular disease (the Heart Protection
Study), a trend towards reduced respiratory death (30\% reduction) and reduced COPD exacerbations (20\% reduction) was reported [110]. The only RCT of statin therapy specifically in patients with COPD was reported from 125 patients in Taiwan and showed that those randomised to pravastatin for 6 months had a 54\% increase in exercise tolerance [111]. Therefore, both observational and randomised studies have reported clinically important benefits of statin therapy in patients with COPD. What is more compelling is that, in the absence of further confirmatory RCT data, the known pharmacological actions of statins on systemic and pulmonary inflammation can explain all the beneficial effects reported to date (table 1).

\section{STATINS EFFECTS ON SYSTEMIC INFLAMMATION IN COPD}

In a prior review, YounG et al. [38] argued that impaired lung function is a strong predictor of cardiovascular death, both independent of and additive with the risk conferred by smoking. It has also been proposed that CAD in patients with COPD results, in part, from the spill over effect of pulmonary derived inflammatory cytokines (e.g. IL-6 and TNF- $\alpha$ ) underlying COPD [4, 7]. As stated previously, both cross sectional and prospective studies show that serum CRP and IL-6 are inversely related to FEV1 implying a possible causal relationship [54-56]. A recent study showed that, at a therapeutic dose, 
TABLE 2 Mortality benefit of statin use in the general population diagnosed with community acquired pneumonia

\begin{tabular}{|c|c|c|c|c|}
\hline Cohort & Subject $n$ & & Risk reduction & [Ref.] \\
\hline Retrospective cohort study in teaching hospital & 787 & $0.36(0.14-0.92)$ & $64 \%$ reduction in 30 -day mortality & [102] \\
\hline Population based retrospective nested case-control & 6089 & $0.47(0.25-0.88)$ & $53 \%$ reduction in fatal pneumonia & [104] \\
\hline Prospective hospital based observational study & 1007 & $0.46(0.25-0.85)$ & $54 \%$ reduction in 30 -day mortality & {$[105]$} \\
\hline Population based cohort study & 29900 & $0.69(0.58-0.82)$ & $31 \%$ reduction in 30 -day mortality & {$[106]$} \\
\hline Population based case-control study & 2235 & $0.81(0.46-1.42)$ & $\begin{array}{l}19 \% \text { reduction in risk of pneumonia (after excluding } \\
\text { those with CAD) }\end{array}$ & {$[108]$} \\
\hline \multirow[t]{2}{*}{ Population based cohort study } & 3681 & $0.33(0.19-0.58)$ & $67 \%$ reduction in 30 -day mortality & {$[109]$} \\
\hline & & $0.45(0.32-0.62)$ & $55 \%$ reduction in long-term mortality & \\
\hline
\end{tabular}

Data are presented as odds ratio (95\% confidence interval). Data for population based case-control study and cohort study are presented as hazard ration (95\% confidence interval). ICU: intensive care unit; CAD: coronary artery disease.

statin therapy was associated with a 50\% reduction in GTPase (Rho) activity of circulating polymorphic neutrophils that correlated with a reduction in serum CRP [112]. NOHRIA et al. [112] proposed that this effect might explain the significant mortality reduction seen with statin use in subjects with normal lipids (Jupiter RCT [113]), which again correlated with CRP reduction [113]. In summary, when statins inhibit systemic inflammation (e.g. CRP and IL-6 derived from pulmonary inflammation), a clinically important reduction in mortality can be achieved. As death from CAD is common in COPD patients $[7,53,66]$ and reduced FEV1 is itself a marker of increased CAD risk, it could be argued that on this basis alone statins might be prescribed for patients with COPD.

Patients with COPD may be profoundly limited by exertional breathlessness attributed, in a large part, to skeletal muscle wasting and atrophy. This limitation of physical activity is not in keeping with airflow limitation (FEV1) and has been attributed to the combined effects of elevated oxidative stress and IL-6, i.e. another systemic inflammation based comorbidity $[7,17-22]$. In the only RCT of statin therapy in COPD, statin use was associated with a $54 \%$ increase in exercise tolerance [111]. This increase correlated with a reduction in high sensitivity-CRP and IL-6 suggesting a reduction in systemic inflammation mediated this clinically important end-point [111]. The question remains, through what mechanisms could statins modify pulmonary inflammation and related remodelling effects in patients with COPD (or even smokers with mild airflow limitation) in addition to traditional inhaler therapies?

\section{STATIN EFFECTS ON PULMONARY INFLAMMATION IN COPD}

It has been recently appreciated that statins have profound antiinflammatory effects that might explain their beneficial role in reducing respiratory morbidity and mortality in COPD (table 1) [66-101, 114-121]. Studies have shown that statins reduce neutrophil influx in the lung which might have a strong effect on attenuating the downstream inflammatory events, such as macrophage influx, lymphocyte activation and inhibition of cytokine release, in particular IL- 8 that appears central to the neutrophil inflammation of the lung [67-77, 80-88]. The inhibition of IL-6, IL-8 and GM-CSF expression by statins has been shown in cell cultures of human BEC $[65,70]$. Statins have also been shown to modify airway inflammation in animal models and matrix remodelling, notably inhibiting emphysema formation [73-75]. Statins also have effects on IL-6 levels in the systemic circulation and the effects of anti-oxidants on muscle atrophy [70, 73-77, 80, 87, 88]. Statins also inhibit apoptosis, which has been linked to both COPD and lung cancer [83-86, 116]. The many pathways affected by statins are shown in figures 1 and 2, where the site of an inhibitory effect of statins based on animal or human studies are clearly shown (table 1).

Statins could conceivably affect these pathways through their inhibition of intracellular prenylation and inhibition of the GTP-binding proteins that underlie these inflammatory pathways $[76,117,118]$. Given these diverse actions on key components of the pathways underlying COPD, it is possible that such effects might explain the benefits observed in the observational studies. In particular, if statins reduce the release of IL-8 in the lungs of COPD patients, then attenuation of neutrophilic inflammation could have considerable downstream effects, such as reduced inflammatory cells in the lungs [81] and reduced remodelling of lung tissue to restore elastin content relative to collagen. If statins reduce the oxidant burden in the systemic circulation $[87,88]$ and the catabolic state conferred by IL- 6 release, then wasting and respiratory muscle function might be improved [21, 22, 87, 88]. It is interesting to note that the inhibitory effect of statins in hepatocytes in blocking cholesterol synthesis might also block cytokine production (primarily IL-6), underlying the premature aging and associated morbidities from smoking-induced systemic inflammation [21].

Statins have also been shown in murine models, through inhibition of GTPase (prenylation), to reverse the hypoxiainduced pulmonary hypertension [119, 120]; a known late complication of COPD causing heart failure. Given the suspected relationship between inflammation, apoptosis and malignant transformation (particularly EMT), it is possible that 
statin therapy may have chemo-preventive actions on lung cancer [28, 85]; as suggested by the three large observational studies reporting up to a $50 \%$ reduction in lung cancer risk (fig. 3) [96-98].

Further support for the protective role of statins on lung inflammation comes from lung transplant studies that show concomitant use of statins reduces post-transplant bronchiolitis and improves lung function compared to patients not receiving statins $[70,76,82,121]$. This is an inflammatorybased complication of lung transplantation with over lapping pathology with COPD, including small airway inflammation dominated by airway fibrosis (bronchiolitis obliterans). Similar pharmacological effects from statins on tissue inflammation and remodelling has been seen in atherosclerosis [122-124] and cardiac transplantation [125].

\section{SUMMARY}

Current therapy in COPD relieves symptoms and reduces hospitalisation but does not change the natural history of the disease (pulmonary inflammation, systemic inflammation and lung function decline) or outcome (respiratory mortality, cardiovascular mortality or all-cause mortality) [50, 126]. Statin therapy may improve all these outcomes to some degree, as suggested by an extensive review of the observational studies [66] and two recent systematic reviews [99, 100], which all consistently show benefit over harm. A large RCT, underpowered to address a statin effect on respiratory outcomes, showed a trend towards lower respiratory death and COPD exacerbations [110]. A small RCT of statin therapy in COPD patients showed an improvement in exercise tolerance [111], probably mediated through systemic inflammation [4, 7, 49]. Clearly, large RCTs are needed to specifically test these potential benefits in patients with COPD. However, based merely on the robust observation that reduced FEV1 is an independent marker of cardiovascular disease and that the latter is a common cause of death in patients with COPD, statin therapy could be initiated for this indication alone $[7,39,66]$. Based on new incites into the pleiotropic effects of statins on matrix remodelling, response to oxidant load and, most importantly, cytokine driven inflammation in the lung and circulation (spill over effect) [4, 7], there is compelling evidence to suggest statins may confer considerably wider benefits to patients with COPD.

\section{STATEMENT OF INTEREST}

None declared.

\section{REFERENCES}

1 Spurzem JR, Rennard SI. Pathogenesis of COPD. Semin Respir Crit Care Med 2005; 26: 142-153.

2 Altose MD. Approaches to slowing the progression of COPD. Curr Opin Pulm Med 2003; 9: 125-130.

3 Mannino DM, Watt G, Hole D, et al. The natural history of chronic obstructive pulmonary disease. Eur Respir J 2006; 27: 627-643.

4 Gan WQ, Man SFP, Senthilselvan A, et al. Association between chronic obstructive pulmonary disease and systemic inflammation: a systematic review and a meta-analysis. Thorax 2004; 59: $574-580$.
5 Yende S, Waterer GW, Tolley EA, et al. Inflammatory markers are associated with ventilatory limitation and muscle dysfunction in obstructive lung disease in well functioning elderly subjects. Thorax 2006; 61: 10-16.

6 Sin DD, Man PSF. Why are patients with chronic obstructive pulmonary disease at increased risk of cardiovascular disease? The potential role of systemic inflammation in chronic obstructive pulmonary disease. Circulation 2003; 107: 1514-1519.

7 Barnes PJ, Celli BR. Systemic manifestations and comorbities in COPD. Eur Respir J 2009; 33: 1165-1185.

8 Rennard SI. Inflammation in COPD: a link to systemic comorbidities. Eur Respir Rev 2007; 16: 91-97.

9 Stockley RA. Neutrophils and the pathogenesis of COPD. Chest 2002; 121: Suppl. 5, 151S-155S.

10 Iho S, Tanaka $Y$, Takauji R, et al. Nicotine induces human neutrophils to produce IL-8 through the generation of peroxynitrite and subsequent activation of NF- $\kappa$ B. J Leukoc Biol 2003; 74: 942-951.

11 Abboud RT, Vimalanathan S. Pathogenesis of COPD. Part I. The role of protease-antiprotease imbalance in emphysema. Int $J$ Tuberc Lung Dis 2008; 12: 361-367.

12 Roth M. Pathogenesis of COPD. Part III. Inflammation in COPD. Int J Tuberc Lung Dis 2008; 12: 375-380.

13 Langen RCJ, Korn SH, Wouters EFM. ROS in the local and systemic pathogenesis of COPD. Free Radic Biol Med 2003; 35: 226-35.

14 MacNee W, Rahman I. Is oxidative stress central to the pathogenesis of chronic obstructive pulmonary disease? Trends Mol Med 2001; 7: 55-62.

15 Tetley TD. Macrophages and the pathogenesis of COPD. Chest 2002; 121: Suppl. 5, 156S-159S.

16 Roman J, Ritzenthaler JD, Gil-Acosta A, et al. Nicotine and fibronectin expression in lung fibroblasts: implications for tobacco-related lung tissue remodeling. FASEB J 2004; 18: 1436-1438.

17 Carlisle DL, Hopkins TM, Gaither-Davis A, et al. Nicotine signals through muscle-type and neuronal nicotinic acetylcholine receptors in both human bronchial epithelial cells and airway fibroblasts. Respir Res 2004; 5: 1-16.

18 Demedts IK, Demoor T, Bracke KR, et al. Role of apoptosis in the pathogenesis of COPD and pulmonary emphysema. Respir Res 2006; 7: 53.

19 Brown V, Elborn JS, Bradley J, et al. Dysregulated apoptosis and NF-кB expression in COPD subjects. Respir Res 2009; 10: 24

20 Kucharczak J, Simmons MJ, Fan Y, et al. To be, or not to be: NFкB is the answer - role of Rel/NF-kappaB in the regulation of apoptosis. Oncogene 2003; 22: 8961-8982.

21 Martinez FJ, MeiLan KH, Andrei AC, et al. Longitudinal change in the Bode index predicts mortality in severe emphysema. Am J Respir Crit Care Med 2008; 178: 491-499.

22 Hansen MJ, Gualano RC, Bozinovski S, et al. Therapeutic prospects to treat skeletal muscle wasting in COPD (chronic obstructive lung disease). Pharmacol Ther 2006; 109: 162-172.

23 Magio M, Guralnik JM, Longo DL, et al. Interleukin-6 in aging and chronic disease: a magnificent pathway. J Gerontol A Biol Sci Med Sci 2006; 61: 575-584.

24 Wilson DO, Weissfeld JL, Balkan A, et al. Association of radiographic emphysema and airflow obstruction with lung cancer. Am J Respir Crit Care Med 2008; 178: 738-744.

25 Young RP, Hopkins RJ, Christmas T, et al. COPD prevalence is increased in lung cancer, independent of age, sex and smoking history. Eur Respir J 2009; 34: 380-386.

26 de Torres J, Bastarrika G, Wisnivesky JP, et al. Assessing the relationship between lung cancer risk and emphysema detected on low dose CT of the chest. Chest 2007; 132: 1932-1938.

27 Mattson ME, Pollack ES, Cullen JW. What are the odds that smoking will kill you? Am J Pub Health 1987; 77: 425-431. 
28 Young RP, Hopkins RJ, Hay BJ, et al. Lung cancer gene associated with COPD: triple whammy or possible confounding effect? Eur Respir J 2008; 32: 1158-1164.

29 Dasari V, Gallup M, Maltseva I, et al. Epithelial-mesenchymal transition in lung cancer: is tobacco the "smoking gun?". Am J Respir Cell Mol Biol 2006; 35: 3-9.

30 Shintani Y, Maeda M, Chaika N, et al. Collagen I promotes epithelial-to-mesenchymal transition in lung cancer cells via transforming growth factor- signaling. Am J Respir Cell Mol Biol 2008; 38: 95-104.

31 Kissil JL, Walmsley MJ, Hanlon L, et al. Requirement for Rac1 in a K-Ras-induced lung cancer in the Mouse. Cancer Res 2007; 67: 8089-8094.

32 Zondag GCM, Evers EE, ten Klooster JP, et al. Oncogene Ras down-regulates Rac activity, which leads to increased Rho activity in epithelial-mesenchymal transition. J Cell Biol 2000; 149: 775-782.

33 Barnes PJ, Karin M. Nuclear factor- $\kappa$ B: a pivotal transcription factor in chronic inflammatory diseases. N Eng J Med 1997; 336: 1066-1071.

34 Redline S, Tishler PV, Rosner B, et al. Genotypic and phenotypic similarities in pulmonary function among family members of adult monozygotic and dizygotic twins. Am J Epidemiol 1989; 129: 827-836.

35 Wilk JB, Djousse L, Arnett DK, et al. Evidence for major genes influencing pulmonary function in the NHLBI family heart study. Genet Epidemiol 2000; 19: 81-94.

36 Hoidal JR. Genetic of COPD: present and future. Eur Respir J 2001; 18: 741-743.

37 Weinshilboum R. Inheritance and drug response. $N$ Eng J Med 2003; 348: 529-537.

38 Young RP, Hopkins RJ, Eaton TE. Forced expiratory volume in one second: not just a lung function test but a marker of premature death from all causes. Eur Respir J 2007; 30: 616-622.

39 Fletcher C, Peto R. The natural history of chronic airflow obstruction. BMJ 1977; 1: 1645-1648.

40 Lokke A, Lange P, Scharling H, et al. Developing COPD: a 25 year follow up study of the general population. Thorax 2006; 61: 935-939.

41 Stav D, Raz M. Prevalence of chronic obstructive pulmonary disease among smokers aged 45 and up in Israel. Isr Med Assoc J 2007; 9: 800-802.

42 Molfino NA. Genetics of COPD. Chest 2004; 125: 1929-1940.

43 Tockman MS, Comstock GW. Respiratory risk factors and mortality: longitudinal studies in Washington County, Maryland. Am Rev Respir Dis 1989; 140: S56-S63.

44 Olofson J, Skoogh BE, Bake B, et al. Mortality related to smoking habits, respiratory symptoms and lung function. Eur J Respir Dis 1987; 71: 69-76.

45 Yanbeva DG, Detener MA, Creutzberg EC, et al. Systemic inflammation in COPD: is genetic susceptibility a key factor. COPD 2006; 3: 51-61.

46 Hattotuwa KL, Gizycki MJ, Ansari TW, et al. The effects of inhaled fluticasone on airway inflammation in chronic obstructive pulmonary disease: a double-blind placebo-controlled biopsy study. Am J Respir Crit Care Med 2002; 165: 1592-1596.

47 Calverley PMA, Anderson JA, Celli B, et al. Salmeterol and fluticasone propionate and survival in chronic obstructive pulmonary disease. N Engl J Med 2007; 356: 775-789.

48 Lung Health Study Research Group. Effect of inhaled triamcinolone on the decline in pulmonary function in chronic obstructive pulmonary disease. N Eng J Med 200, 343: 1902-1909.

49 Sin DD, Man SFP. Skeletal muscle weakness, reduced exercise tolerance, and COPD: is systemic inflammation the missing link? Thorax 2006; 61: 1-3.

50 Roche N. Where current pharmacological therapies fall short in COPD: symptom control is not enough. Eur Respir Rev 2007; 16: 98-104.
51 Cazzola M, Ciaprini $\mathrm{C}$, Page $\mathrm{CP}$, et al. Targeting systemic inflammation: novel therapies for treatment of chronic obstructive pulmonary disease. Expert Opin Ther Targets 2007; 11: 1273-1286.

52 Hothersall E, McSharry C, Thomson NC. Potential therapeutic role for statins in respiratory disease. Thorax 2006; 61: 729-734.

53 Walsh GM. Statins as emerging treatments for asthma and chronic obstructive pulmonary disease. Expert Rev Respir Med 2008; 2: 329-335.

54 Pinto-Plata VM, Mullerova H, Toso JF, et al. C-reactive protein in patients with COPD, control smokers and non-smokers. Thorax 2006; 61: 23-28.

55 Gan WQ, Man SFP, Sin DD. The interactions between cigarette smoking and reduced lung function on systemic inflammation. Chest 2005; 127: 558-564.

56 Rasmussen F, Mikkelsen D, Hancox RJ, et al. High-sensitive Creactive protein is associated with reduced lung function in adults. Eur Respir J 2009; 33: 382-388.

57 Walker RE, Wilk JB, Larsen MG, et al. Systemic inflammation and COPD: the Framingham Heart Study. Chest 2008; 133: 19-25.

58 Sin DD, Man SFP Interluekin 6, Chest 2008; 133: 4-6.

59 Kuhn C, Homer RJ, Zhu Z, et al. Airway responsiveness and airway obstruction in transgenic mice: morphologic correlates in mice overexpressing IL-11 and IL-6 in the lung. Am J Respir Cell Mol Biol 2000; 22: 289-295.

60 He J-Q, Foreman MG, Shumansky K, et al. Associations of IL-6 polymorphisms with lung function decline and COPD. Thorax 2009; 64: 698-704.

61 Amos CI, Wu X, Broderick P, et al. Genome-wide association scan of tag SNPs identifies a susceptibility locus for lung cancer at 15q25.1. Nat Genet 2008; 40: 616-622.

62 Young RP, Hopkins RJ, Bay BA, et al. Lung cancer susceptibility model based on age, family history and genetic variants. PLOS One 2009; 4: e5302.

63 Schonbeck U, Libby P. Inflammation, immunity, and HMG-CoA reductase: inhibitors: statins as anti-inflammatory agents? Circulation 2004; 109: I118-I126.

64 Melbye H, Halvorsen DS, Hartz I, et al. Bronchial airflow limitation, smoking, body mass index, and statin use are strongly associated with the C-reactive protein level in the elderly. The Tromsø Study 2001. Respir Med 2007; 101: 2541-2549.

65 Hurst JR, Hagan G, Wedzicha JA. Mechanism of statinassociated mortality reduction in COPD. Chest 2007; 132: 1409.

66 Young RP, Hopkins RJ, Eaton TE. Potential benefits of statins on morbidity and mortality in COPD: a review of the evidence. Postgrad Med J 2009; 85: 414-421.

67 Arnaud C, Burger F, Steffens S, et al. Statins reduce interleukin-6induced c-reactive protein in human hepatocytes: new evidence for direct antiinflammatory effects of statins. Arterioscler Thromb Vasc Biol 2005; 25: 1231-1236.

68 Ikeda U, Shimada K. Statins and monocytes. Lancet 1999; 353: 2070

69 Takayuki I, Ikeda U, Yamamoto K, et al. Regulation of interleukin-8 expression by HMG-CoA reductase inhibitors in human vascular smooth muscle cells. Atherosclerosis 2002; 165: 51-55.

70 Murphy DM, Forrest IA, Corris PA, et al. Simvastatin attenuates release of neutrophilic and remodeling factors from primary bronchial epithelial cells derived from stable lung transplant recipients. Am J Physiol Lung Cell Mol Physiol 2008; 294: L592-L599.

71 Xue-Mei O, Bai-ding W, Fu-qiang W, et al. Simvastatin attenuates lipopolysaccharide-induced airway mucus hyper-secretion in rats. Chin Med J 2008; 121: 1680-1687.

72 Ferro D, Parrotto S, Basili S, et al. Simvastatin inhibits the monocyte expression of proinflammatory cytokines in patients with hypercholesterolemia. J Am Coll Cardiol 2000; 36: 427-431.

73 Takahashi S, Nakamura H, Furuuchi M, et al. Simvastatin suppresses the development of elastase-induced emphysema in mice (abstract). Proc Am Thor Soc 2005; 2: A135. 
74 Lee JH, Lee DS, Kim EK, et al. Simvastatin inhibits cigarette smoking-induced emphysema and pulmonary hypertension in rat lungs. Am J Respir Crit Care Med 2005; 172: 987-993.

75 Takahashi S, Nakamura H, Seki M, et al. Reversal of elastaseinduced pulmonary emphysema and promotion of alveolar epithelial cell proliferation by simvastatin in mice. Am J Physiol Lung Cell Mol Physiol 2008; 294: L882-L890.

76 Maher BM, Ni Dhonnchu T, Burke JP, et al. Statins alter neutrophil migration by modulating cellular Rho activity - a potential mechanism for statins-mediated pleiotropic effects? J Leukoc Biol 2009; 85: 186-193.

77 Guasti L, Marino F, Cosentino M, et al. Simvastatin treatment modifies polymorphonuclear leukocyte function in high-risk individuals: a longitudinal study. J Hypertens 2006; 24: 2423-2430.

78 Kimura M, Kurose I, Russel J, et al. Effects of fluvastatin on leukocyte endothelial cell adhesion in hypercholesterolaemic mice. Arterioscler Thromb Vasc Biol 1997; 17: 1521-1526.

79 Scalia R, Gooszen ME, Jones SP, et al. Simvastatin exerts both anti-inflammatory and cardioprotective effects on apolipoprotein E-deficient mice. Circulation 2001; 103: 2598-2603.

80 Chello M, Patti G, Candura D, et al. Effects of atorvastatin on systemic inflammatory response after coronary bypass surgery. Crit Care Med 2006; 34: 660-667.

81 Montecucco F, Burger F, Pelli G, et al. Statins inhibit C-reactive protein-induced chemokine secretion, ICAM-1 up-regulation and chemotaxis in adherent human monocytes. Rheumatology 2009; 48: 233-242.

82 Nishibori M, Takahashi HK, Mori S. The regulation of ICAM-1 and LFA-1 interaction by autacoids and statins: a novel strategy for controlling inflammation and immune responses.J Pharmacol Sci 2003; 92: 7-12.

83 Jacobson JR, Barnard JW, Grigoryev DN, et al. Simvastatin attenuates vascular leak and inflammation in murine inflammatory lung injury. Am J Physiol Lung Cell Mol Physiol 2005; 288: L1026-L1032.

84 Frick M, Dulak J, Cisowski J, et al. Statins differentially regulate vascular endothelial growth factor synthesis in endothelial and vascular smooth muscle cells. Atherosclerosis 2003; 170: 229-236.

85 Morimoto K, Janssen WJ, Fessler MB, et al. Lovastatin enhances clearance of apoptotic cells (efferocytosis) with implications for chronic obstructive pulmonary disease. J Immunol 2006; 176: $7657-7665$

86 Newton CJ, Ran G, Xie YX, et al. Statin induced apoptosis of vascular endothelial cells is blocked by dexamethasone. Endocrinol 2002; 174: 7-16.

87 Shishehbor MH, Brennan ML, Aviles RJ, et al. Statins promote potent systemic antioxidant effects through specific inflammatory pathways. Circulation 2003; 108: 426-431.

88 Rikitake Y, Kawashima S, Takeshita S, et al. Anti-oxidative properties of fluvastatin, an HMG-CoA reductase inhibitor, contribute to prevention of atherosclerosis in cholesterol-fed rabbits. Atherosclerosis 2001; 154: 87-96.

89 Mancini GBJ, Etminan M, Zhang B, et al. Reduction of morbidity and mortality by statins, angiotensin-converting enzyme inhibitors, and angiotensin receptor blockers in patients with chronic obstructive pulmonary disease. I Am Coll Cardiol 2006; 47: 2554-2560.

90 Keddissi JI, Younis WG, Chbeir EA, et al. The use of statins and lung function in current and former smokers. Chest 2007; 132 1764-1771.

91 van Gestel YRBM, Hoeks SE, Sin DD, et al. Effect of statin therapy on mortality in patients with peripheral arterial disease and comparison of those with versus without associated chronic obstructive pulmonary disease. Am I Cardiol 2008; 102: 192-196.

92 Soyseth V, Brekke PH, Smith P, et al. Statin use is associated with reduced mortality in COPD. Eur Respir J 2007; 29: 279-283.
93 Frost FJ, Petersen H, Tollestrup K, et al. Influenza and COPD mortality protection as pleiotropic, dose-dependent effects of statins. Chest 2007; 131: 1006-1012.

94 Mortensen EM, Copeland LA, Pugh MJ, et al. Impact of statins and ACE inhibitors on mortality after COPD exacerbations. Respir Res 2009; 10: 45.

95 Blamoun AI, Batty GN, DeBari VA, et al. Statins may reduce episodes of exacerbation and the requirement for intubation in patients with COPD; evidence from a retrospective cohort study. Int J Clin Prac 2008; 62: 1373-1378.

96 Khurana V, Bejjanki HR, Caldito G, et al. Statins reduce the risk of lung cancer in humans: a large case-control study of US veterans. Chest 2007; 131: 1282-1288.

97 Farwell WR, Scranton RE, Lawler EV, et al. The association between statins and cancer incidence in a veterans population. $J$ Natl Cancer Inst 2008; 100: 134-139.

98 Karp I, Behlouli $\mathrm{H}$, LeLorier J, et al. Statins and cancer. Am J Med 2008; 121: 302-309.

99 Janda S, Park K, Fitzgerald JM, et al. Statins in COPD: a systemic review. Chest 2009; 136: 734-743.

100 Dobler CC, Wong KK, Marks GB. Association between statins and COPD: a systematic review. BMC Pulm Med 2009; 9: 32.

101 Alexeeff SE, Litonjua AA, Sparrow D, et al. Statin use reduces decline in lung function: VA Normative Aging Study. Am J Respir Crit Care Med 2007; 176: 742-747.

102 Mortensen EM, Restrepo MI, Anzueto A, et al. The effect of prior statin use on 30-day mortality for patients hospitalised with community acquired pneumonia. Respir Res 2005; 6: 82.

103 Majumdar SR, McAlister FA, Eurich DT, et al. Statins and outcomes in patients admitted to hospital with community acquired pneumonia: population based prospective cohort study. BMJ 2006; 333: 999.

104 Schlienger RG, Fedson DS, Jick SS, et al. Statins and the risk of pneumonia: a population based nested case control study. Phrmacotherapy 2007; 27: 325-332.

105 Charmers JD, Singanayagam A, Murray MP, et al. Prior statin use is associated with improved outcomes in community acquired pneumonia. Am J Med 2008; 121: 1002-1007.

106 Thomsen RW, Rus A, Kormun JB, et al. Preadmission use of statins and outcomes after hospitalisation with pneumonia: population based cohort study of 29900 patients. Arch Intern Med 2008; 168: 2081-2087.

107 Mortensen EM, Pugh MJ, Copeland LA, et al. Impact of statins and angiotensin-converting enzyme inhibitors on mortality of subjects hospitalised with pneumonia. Eur Respir J 2008; 31: 611-617.

108 Dublin S, Jackson ML, Nelson JC, et al. Statin use and risk of community acquired pneumonia in older people: population based case-control study. BMJ 2009; 338: b2137.

109 Myles PR, Hubbard RB, Gibson JE, et al. The impact of statins, ACE inhibitors and gastric acid suppresants on pneumonia moertaility in a UK general practice population cohort. Pharmacoepidemiol Drug Saf 2009; 18: 697-703.

110 Heart Protection Study collaborative Group. The effects of cholesterol lowering with simvastatin on cause-specific mortality and on cancer incidence in 20,536 high-risk people: a randomized placebo-controlled trial [ISRCTN48489393]. BMC Med 2005; 3: 6 .

111 Lee T-M, Lin M-S, Chang N-C. Usefulness of C-reactive protein and interleukin-6 as predictors of outcomes in patients with chronic obstructive pulmonary disease receiving pravastatin. Am J Cardiol 2008; 101: 530-535.

112 Nohria A, Prsic A, Liu P-Y, et al. Statins inhibit Rho kinase activity in patients with atherosclerosis. Atherosclerosis 2009; 205 517-521.

113 Ridker PM, Danielson E, Fonseca FAH, et al. Rosuvastatin to prevent vascular events in men and women with elevated Creactive protein. N Eng J Med 2008; 359: 2195-2207. 
114 Weitz-Schmidt G, Welzenbach K, Brinkmann V, et al. Statins selectively inhibit leukocyte function antigen-1 by binding to a novel regulatory integrin site. Nature Med 2001; 7: 687-692.

115 Takahashi HK, Mori S, Iwagaki H, et al. Differential effect of LFA703, proavastatin, and fluvastatin on production of IL-18 and expression of ICAM-1 and CD40 in human monocytes. J Leukoc Biol 2005; 77: 400-407.

116 Wei CY, Huang KC, Chou YH, et al. The role of Rho-associated kinase in differential regulation by statins of IL-1B and LPSmediated NFKB activation and iNOS gene expression in vascular smooth muscle cells. Mol Pharmacol 2006; 69: 960-967.

117 Liao JK. Clinical implications for statin pleiotropy. Curr Opin Lipidol 2005; 16: 624-629.

118 Iwata A, Shirai R, Umeki K, et al. Anti-inflammatory effect of statins on human bronchial epithelial cells. American Thoracic Society, San Diego 2009. A3735.

119 Girgis RF, Mozammel S, Champion HC, et al. Regression of chronic hypoxic pulmonary hypertension by simvastatin. Am J Physiol Lung Cell Mol Physiol 2007; 292: L1105-L1110.
120 Hsu HH, Ko WJ, Hsu JY, et al. Simvastatin ameliorates established pulmonary hypertension through a hemeoxygenase- 1 dependent pathway in rats. Respir Res 2009; 10: 32.

121 Johnson BA, Iacono AT, Zeevi A, et al. Statin use is associated with improved function and survival of lung allografts. Am J Respir Crit Care Med 2003; 167: 1271-1278.

122 Bellosta S, Via D, Canavesi P, et al. HMGCoA reductase inhibitors reduce MMP-9 secretion by macrophages. Arterioscler Thromb Vasc Biol 1998; 18: 1671-1678.

123 Ikeda U, Shimpo M, Ohki R, et al. Fluvastatin inhibits matrix metalloproteinase-1 expression in human vascular endothelial cells. Hypertension 2000; 36: 325-329.

124 Black M. Atherosclerosis, COPD and chronic inflammation. Respir Med 2008: 4; 60-65.

125 Mehra MR, Raval NY. Meta-analysis of statins and survival in de novo cardiac transplantation. Transplant Proc 2004; 36: 1539-1541.

126 Cazzola M. From large clinical trials to management of COPD in the real world. Ther Adv Respir Dis 2009; 3: 39-46. 